\title{
The influence of stereochemistry of the active compounds on fluoride adsorption efficiency of the plant biomass
}

\author{
Hezron T Mwakabona, Revocatus L Machunda, Karoli N Njau* \\ Nelson Mandela African Institution of Science and Technology (NM-AIST), Arusha, Tanzania \\ Email addresses: \\ mwakabonah@nm-aist.ac.tz (H. T. Mwakabona), revocatus.machunda@nm-aist.ac.tz (R. L. Machunda), \\ karoli.njau@nm-aist.ac.tz (K. N. Njau)
}

\section{To cite this article:}

Hezron T Mwakabona, Revocatus L Machunda, Karoli N Njau. The Influence of Stereochemistry of the Active Compounds on Fluoride Adsorption Efficiency of the Plant Biomass. American Journal of Chemical Engineering Vol. 2, No. 4, pp. $42-47$.

doi: $10.11648 /$ j.ajche.20140204.12

\begin{abstract}
Several studies have reported various defluoridation capabilities of plant biomasses. The resultant variations in fluoride removal capacities are associated with the presence of different types of active functional groups in the respective biomasses. This study reports of the fluoride removal efficiencies of sisal leaf biomass in comparison. Comparison with other plant biomasses were made and hence the fluoride removal efficiencies of maize leaf (ML), goose grass (GG), banana false stem (BFS), Aloe vera (AV), untreated sisal fibre (USF) and sisal pith (SP) with similar active functional groups but different stereochemistry and solubility of the active compounds are reported. A portion of $0.5 \mathrm{~g}$ of each biomass was mixed with a 10 $\mathrm{mg} / \mathrm{l}$ fluoride solution in a $10 \mathrm{ml}$ portions under the same experimental conditions. The maximum fluoride removal capacity of sisal fibre biomass was found to be $26.6 \%$. By comparison, the fluoride removal efficiencies of ML, GG, BFS, AV, USF and SP were found to be, 4.1, 4.6, 7.1, 26.6, 29.4 and $47.3 \%$ respectively. This suggests that, stereochemistry and solubility of the active compounds have a significant role to play in water defluoridation by plant biomasses, and thus, knowledge of the stereochemistry and solubility of the active compounds in plant biomass is very important to fully unlock biomass' defluoridation potentials.
\end{abstract}

Keywords: Stereochemistry, Plant Biomass, Sisal Pith, Sisal Fibre, Inulin

\section{Introduction}

Fluorosis is a common disease in fluorotic areas characterized by mottling of teeth and deformation of skeletal bones in mild and severe cases respectively [1]. The sole culprit behind this is fluoride, mainly in drinking water. Thus, the most effective way of cutting down the occurrence of fluorosis would involve defluoridation of drinking water $[1,2]$

Several defluoridation techniques with various successes are reported [3-5]. These include; adsorption/ion exchange, precipitation/coagulation, reverse and forward osmosis, and electrolysis as shown in table 1 . Among these, adsorption seems to be economical and user-friendly especially in the developing world $[3,5]$ where point of use treatment is recommended [1]. Different adsorbents have different limitations; for instance, synthetic ion exchangers are relatively expensive and work better under acidic $\mathrm{pH}$ [3].
This makes difficult for low-income communities to afford one and necessitates the $\mathrm{pH}$ regulation of the treated water before or and after treatment. Bone char is a natural adsorbent prepared from burning of animal bones [1]. It has good fluoride adsorptive capacity even at neutral $\mathrm{pH}$, and can be easily available. However, bone char harbors bacteria and is likely to face natural and religious objections [6]. Moreover, bone char has stringent preparation conditions; thus, require skilful personnel in its preparation and is not available commercially [1]. Natural rock materials are yet another source of fluoride adsorbents $[7,8]$. However, they are accused of introducing unwanted impurities into the treated water [7]. Thus, no wonder that a search for effective low cost defluoridation materials is a continuing concern amongst researchers. 
Table 1. Summary of advantages and disadvantages of some defluoridation methods

\begin{tabular}{|c|c|c|c|c|}
\hline $\mathbf{S} / \mathbf{N}$ & Method & Advantage(s) & Disadvantage(s) & Reference \\
\hline 1 & Ion exchangers & 1. High removal of fluoride $(F)$ & $\begin{array}{l}\text { 1. Expensive } \\
\text { 2. Needs pre and or post treatment } \mathrm{pH} \text { regulation of the treated } \\
\text { water }\end{array}$ & {$[3]$} \\
\hline 2 & Bone char & $\begin{array}{l}\text { 1. Relatively high } \mathrm{F} \text { removal } \\
\text { 2. Works better at neutral } \mathrm{pH}\end{array}$ & $\begin{array}{l}\text { 1. Possible religious and cultural objections } \\
\text { 2. Harbors bacteria } \\
\text { 3. Stringent preparation conditions/require skilled person to prepare } \\
\text { 4.Commercially unavailable }\end{array}$ & {$[1,6,14]$} \\
\hline 3 & Natural rock & $\begin{array}{l}\text { 1. Cheaply available } \\
\text { 2. Good F removal }\end{array}$ & $\begin{array}{l}\text { 1. Introduces other impurities to the treated water } \\
\text { 2. Calls for rigorous pre treatment }\end{array}$ & {$[7,8]$} \\
\hline 4 & Plant biomass & $\begin{array}{l}\text { 1. Widely available } \\
\text { 2. Good } \mathrm{F} \text { removal } \\
\text { Works better at around neutral } \mathrm{pH} \\
\text { 3. Simple preparation procedures } \\
\text { 4. High natural biodegradability }\end{array}$ & $\begin{array}{l}\text { 1. Can introduce organic compounds into water if not well } \\
\text { prepared/selected }\end{array}$ & {$[9-12,14,15]$} \\
\hline 5 & $\begin{array}{l}\text { Nalgonda } \\
\text { Technique }\end{array}$ & $\begin{array}{l}\text { 1. Uses cheap materials } \\
\text { 2. Good F removal }\end{array}$ & $\begin{array}{l}\text { 1. Lime used elevates the } \mathrm{pH} \text { of the treated water } \\
\text { 2. Introduces } \mathrm{Al} \text { in the treated water which can cause Alzheimer's } \\
\text { disease } \\
\text { 3. Need for time to time } \mathrm{F} \text { measurement of the water to be treated }\end{array}$ & {$[1,3,14]$} \\
\hline 6 & Osmosis & 1. High $\mathrm{F}$ removal & 1. High installation and running cost & {$[1,4,5]$} \\
\hline
\end{tabular}

In recent years, there has been an increasing interest in studying defluoridation characteristics of plant biomasses [9-14]. These adsorbents are interesting in that they work optimally at $\mathrm{pH}$ between 6 and 7 [9-12, 15] and are sustainably available earth wide. This implies that there will be no need for pre- and or post- treatment $\mathrm{pH}$ regulation of water when these adsorbents find use in water treatment processes. Additionally, these materials promise availability of cheap and disposable fluoride filters owing to wide distribution and biodegradability of plant biomass. Biomass' fluoride affinity is associated with the presence of such functional groups as $\mathrm{OH}, \mathrm{NH}_{2}, \mathrm{Mg}$ and $\mathrm{Ca}$ in their surfaces $[10,15,16]$.

Although the presence or absence of specific functional groups have a role to play in defluoridation capacities of different plant biomass, it appears that this is not the only influence to the biomass' fluoride removal capacity. For instance, the main chemical composition of bagasse, wheat straw and corn cob biomass is more or less similar [17]. This implies that the functional groups responsible for fluoride adsorption are also similar. However, these kinds of biomass have significantly different fluoride removal capacities $[12,18,19]$. Such discrepancy was also reported by Harikumar et al. [11] in their studies on defluoridation of water by different plant biomass. Their findings reveal that, fluoride removal capacity of vetiver roots and coffee husks are $80 \%$ and $38 \%$ respectively, under the same experimental conditions [11]. This difference in defluoridation capacities of these two kinds of biomass cannot be accounted by the type of functional groups present as there is a small difference in chemical composition of the two [20-23]. This implies that, there are other factors than the type of functional groups that are responsible for biomass' defluoridation capacities.

In this work, defluoridation capacities of six plant biomass; maize leaf (ML), goose grass (GG), banana false stem (BFS), untreated sisal fibre (USF) and the sisal leaf pith (SP) biomass were compared under same experimental conditions. The aim was to establish the influence of stereochemistry and solubility of the active compounds in these kinds of biomass at the optimized defluoridation conditions of sisal fibre. The optimal defluoridation conditions of sisal fibres were determined by establishing the optimal equilibration time, dose, $\mathrm{pH}$ and initial fluoride. These optimal conditions were then used for comparison of the different plant biomass. The defluoridation capacities obtained were compared in light of the stereochemistry and solubility of the active compounds from literature for each type of biomass.

\section{Methodology}

\subsection{Biomass Collection and Preparation}

Sisal leaves and sisal fibres were collected from Magereza sisal processing industry in Morogoro, and the Aloe vera, maize leaves, goose grass and banana false stem were obtained from a nearby farmer. The sisal pith was obtained by pressing and pulling the sisal leaves manually, to separate the fibres from the pith. All plant biomasses were washed with distilled water to remove dust and other impurities then air dried at room temperature of about $24 \pm$ $2^{\circ} \mathrm{C}$ for a week to avoid alteration or destruction of the active compounds by sun rays, followed by oven at $70^{\circ} \mathrm{C}$ 
for two days for ensuring complete drying. AATSF was prepared by soaking sisal fibres in distilled water for a week, washing in $1 \mathrm{M} \mathrm{NaOH}$ solution and then $1 \mathrm{M} \mathrm{HCl}$ acid to remove all water soluble constituents from the fibres then in distilled water till the wash water tested neutral and finally dried in the oven at $70^{\circ} \mathrm{C}$ for two days. The dry biomass were removed from the oven and immediately ground by an electric grinder at 1000 RPM and sieved to obtain the particle size between 150 and 300 micrometer. The ground biomass was kept in airtight polythene bags for further use.

\subsection{Preparation of Reagents}

$100 \mathrm{mg} / \mathrm{l}$ fluoride solution was prepared by appropriate dilution of $1000 \mathrm{mg} / \mathrm{l}$ stock solution (Mettler Toledo Reagent) into distilled water. From this solution, $1 \mathrm{mg} / \mathrm{l}$ and $10 \mathrm{mg} / \mathrm{l}$ standards and other required concentrations were prepared by appropriate dilutions.

\subsection{Adsorption Experiments}

All equilibration experiments were conducted in triplicates. The effect of agitation time was determined by treating $10 \mathrm{ml}$ of $10 \mathrm{mg} / 1$ fluoride solution with $0.5 \mathrm{~g}$ of sisal fibre powder for up to 1440 minutes and drawing samples for analysis after every 5 minutes for the first hour and every 30 minutes from the second to the fourth hour then hourly for the rest of the time. The effect of dose of sisal fibres was determined by treating $10 \mathrm{ml}$ of $10 \mathrm{mg} / \mathrm{l}$ of fluoride solution with known weights of ground sisal fibres from 0.1 to $1 \mathrm{~g}$ of sisal fibre powder at an interval of $0.1 \mathrm{~g}$ between weights to get doses between $10 \mathrm{~g} / \mathrm{l}-100 \mathrm{~g} / \mathrm{l}$. The effect of $\mathrm{pH}$ on the fluoride adsorption by sisal fibres was determined by treating $10 \mathrm{ml}$ of $10 \mathrm{mg} / 1$ with $0.5 \mathrm{~g}$ of sisal fibre with varying $\mathrm{pH}$ from 5 to 9 . The effect of initial fluoride concentration was determined by treating $0.5 \mathrm{~g}$ of sisal fibre powder with $10 \mathrm{ml}$ of varying concentrations of initial fluoride solution between $5-10 \mathrm{mg} / \mathrm{l}$ at an interval of $1 \mathrm{mg} / \mathrm{l}$ between consecutive concentrations at $\mathrm{pH} 6$, since levels above $4 \mathrm{mg} / \mathrm{l}$ of fluoride are reported to have more visible effects to human health than those below $4 \mathrm{mg} / \mathrm{l}$. All equilibration experiments were done strictly in the plastic tubes. Samples were shaken in the incubator-shaker at $25^{\circ} \mathrm{C}$ and 210 revolutions per minute (RPM).

To determine the effect of stereochemistry and solubility of the active compounds on fluoride removal efficiency, different biomasses whose active compounds differ in solubility and stereochemistry of the active functional groups were used in defluoridation of water. For this purpose, $0.5 \mathrm{~g}$ of maize leaf (ML), goose grass (GG), banana false stem (BFS), Aloe vera (AV), untreated sisal leaf fibres (USF) and sisal pith (SP) of the same particle size were added into $10 \mathrm{ml}$ of $10 \mathrm{mg} / \mathrm{l}$ fluoride solution in separate plastic tubes. Then the mixture was shaken for two hours at $210 \mathrm{RPM}$ and $25^{\circ} \mathrm{C}$ in the incubator-shaker for fluoride adsorption to occur.

\section{Results and Discussion}

\subsection{The Effect of Agitation Time}

Agitation time was found to have an effect on the amount of fluoride removed per unit weight of biomass. The fluoride concentrations in the reactors continued to decrease steadily from 0 to 60 minutes for USF and 180 minutes for AATSF, after which it levelled out (Figure 1). This trend was also reported by other studies on defluoridation by plant biomass $[10,12,15]$. This is due to progressive saturation of the active sites with time. This implies that the biomass has specific number of active sites, which eventually are saturated after prolonged exposure to fluoride solution as indicated by a horizontal portion of both fig 1(a) and (b). The curve inclines downward after 160 minutes in figure 1(a), likely due to release of adsorbed fluoride into the solution $[10,24]$ or dissolution of the active compounds into the solution, such as, remaining traces of inulin which are water soluble, in the USF [25]. Prolonged exposure of the biomass into water may lead to dissolution of some active compounds into the solution. On the other hand, the AATSF whose preparation involved washing with alkaline and acidic solutions did not show decline of the fluoride removal as shown in figure 1(b). This trend was also reported in defluoridation by rice husks [15]. This suggests that interaction between fluoride ion and the cellulose lasts longer.

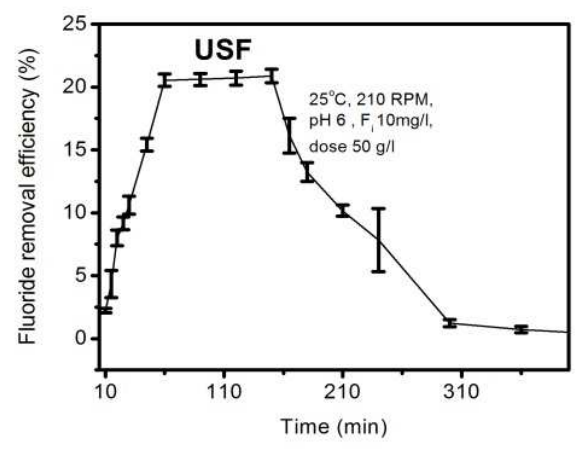

(a)

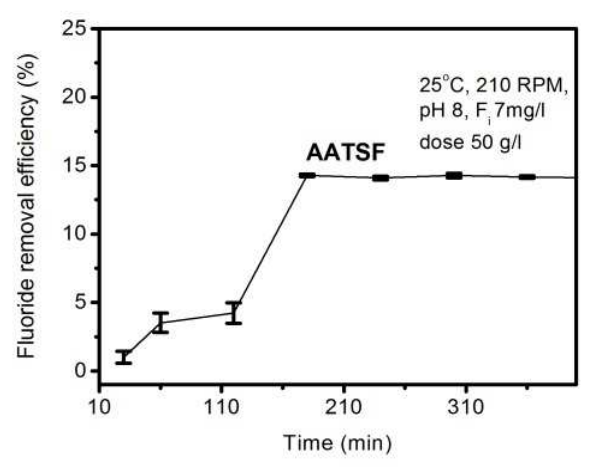

(b)

Figure 1. Effect of agitation time on the fluoride removal efficiency of USF and AATSF at stated conditions 


\subsection{The Effect of Biomass Dose}

The effect of biomass dose is shown in Figure 2, which indicates that the removal of fluoride increases with increase of the biomass dose. This trend was also reported by Vardhan \& Karthkeyan [15] Pandey et al. [10], Kumar et al. [9] and Yadav et al. [12]. The optimal dose was found to be $40 \mathrm{~g} / \mathrm{l}$ with fluoride removal of about $19 \%$ from initial fluoride concentration of $10 \mathrm{mg} / \mathrm{l}$. The increase of fluoride removal with increase of biomass dose can be attributed to increasing number of active sites with increase in the biomass dose $[9,12]$. The levelling out of the removal efficiency after $40 \mathrm{~g} / \mathrm{l}$ is due to possible overlapping of the active sites which masks any further increase in the dose or insufficient driving force responsible for adsorption process $[9-11,15]$.

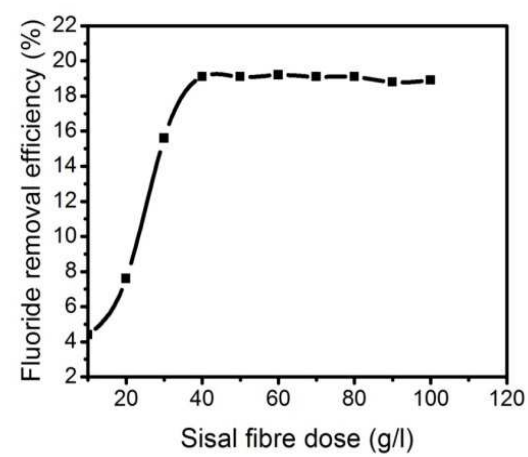

Figure 2. Effect of biomass dose on fluoride removal of sisal fibre at $25^{\circ} \mathrm{C}$, $210 \mathrm{RPM}, \mathrm{pH} \mathrm{6,} 120 \mathrm{~min}$ and $10 \mathrm{mg} / \mathrm{l} \mathrm{F}$

\subsection{The effect of $\mathrm{pH}$}

The role played by $\mathrm{pH}$ is shown in figure 3 . The $\mathrm{pH}$ at which the sisal fibre biomass performs maximally is 5.8-6. This was also observed for Dalbergia, wheat straw and Tamarind fruit cover $[9,12,14]$. In acidic condition, $\mathrm{OH}^{-}$ groups in the biomass can interact with $\mathrm{H}^{+}$in solution to form positively charged surfaces [26], thence, the ionic interaction between the biomass surface and the fluoride ion could be another way fluoride is adsorbed onto the biomass in addition to substitution of the active functional groups [10]. This can account for higher fluoride removal efficiency at acidic than at alkaline medium. Moreover, at around $\mathrm{pH} 8$, the fluoride adsorption rises. This can be due to weak interaction between $\mathrm{OH}$ groups on the surface of the biomass and the $\mathrm{OH}^{-}$ions in the solution. This interaction can lead into the formation of weak positively charged points at the adjacent carbon in the active compounds of the fibre, therefore a weak ionic interaction between fluoride and adjacent carbon. It was also found that, the $\mathrm{pH}$ of all the treated water ranged from 5.7-6.5. This is attributable to the influence of the $\mathrm{pH}$ of the sisal biomass which is about 5.42 to $5.86[14,25,27]$. The decline in the fluoride removal at elevated $\mathrm{pH}$ is attributable to the interference of hydroxyl groups, which in alkaline condition, competes for the active sites with fluoride ions.

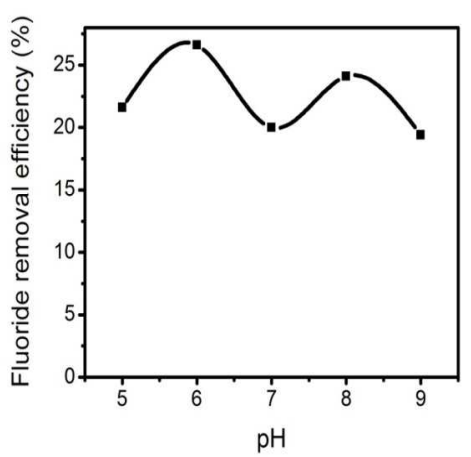

Figure 3. Effect of $\mathrm{pH}$ on fluoride removal efficiency of the sisal fibre at $25^{\circ} \mathrm{C}, 210 \mathrm{RPM}, 120 \mathrm{~min}, 50 \mathrm{~g} / \mathrm{l}$ biomass and $10 \mathrm{mg} / \mathrm{l} \mathrm{F}$

\subsection{The Effect of Initial Fluoride Concentration}

The initial fluoride concentration showed influence on the removal capacity of the biomass, where the amount of fluoride adsorbed increased with increasing initial fluoride concentration from $0.01-0.05 \mathrm{mg} / \mathrm{g}$ at initial concentration ranging from $5-10 \mathrm{mg} / \mathrm{l}$. Similar trends were observed by Yadav et al. [12] and Mondal et al. [28]. This is attributable to the increased concentration gradient between the liquid and the solid phases which increasingly exceeds the mass transfer resistance between the solution and the biomass [12].

\subsection{The effect of Solubility and Stereochemistry of the Active Compounds}

Results of a comparative study of fluoride removal capacities of maize leaves (ML), goose grass (GG), banana false stem (BFS), untreated sisal fibre (USF), Aloe vera (AV) and sisal pith is shown in figure 4 . The fluoride removal efficiencies of ML, GG, BFS, AV, USF and SP were found to be, 4.1, 4.6, 7.1, 26.6, 29.4 and $47.3 \%$ respectively. Significant difference in defluoridation capacities of chemically similar biomass was also reported by Yadav et al [12]. Since both biomass have generally similar active functional groups responsible for interaction with fluoride ion $[17,19,25,27,29-31]$, the observed difference in fluoride removal efficiencies cannot be associated with the type of active functional groups.

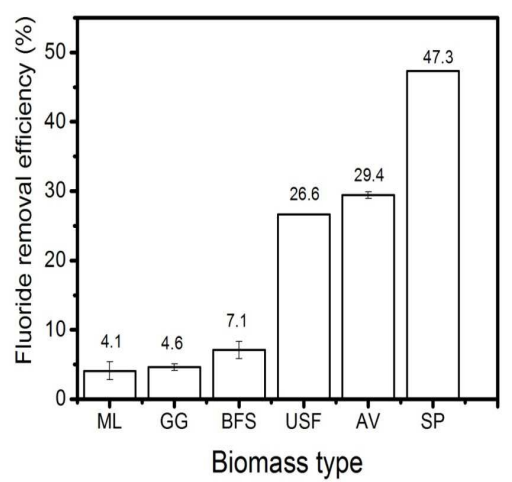

Figure 4. Fluoride removal capacities of sisal fibre and pith at $25^{\circ} \mathrm{C}, 210$ RPM, $50 \mathrm{~g} / \mathrm{l}$ biomass, $120 \mathrm{~min}, \mathrm{pH} 6$ and $10 \mathrm{mg} / \mathrm{l} \mathrm{F}$. 
Literature reveals that, the main difference between the pith and the fibre is the stereochemical structure and solubility of the major active compounds and the amount of ashes in them [25, 27]. However, amount of ash in the biomass seems to have negligible influence in the defluoridation capacity of the plant biomass [12, 17-19]. Thus, the difference in fluoride removal efficiencies observed may be due to the difference in stereochemistry and solubility of the active compounds in the biomass. The major constituent of the pith is inulin which is soluble in water and has an open stereochemistry, whereas that of the sisal fibre is cellulose which is insoluble in water and has a compact stereochemistry as shown in compound a and $\mathrm{c}$ in figure 5 below $[25,32]$. Therefore, the low fluoride removal capacity of sisal fibre may be attributed to the compact stereochemical structures of the cellulose, in which, the orientation of the active functional groups increases the likelihood of the same to be hidden by the overlaying surrounding micro fibrils in the fibres. On the other hand solubility and stereochemical structure of inulin exposes the $\mathrm{OH}$ groups for interaction with fluoride ions.

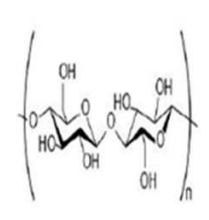

(a) cellulose

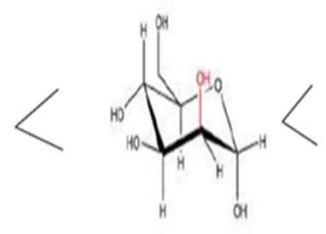

(b) mannose unit

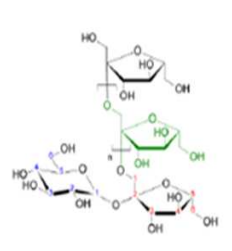

(c) inulin
Figure 5. Different active compounds, their stereochemistry and trend of their fluoride removal efficiencies

Differences in fluoride removal efficiencies of the sisal fibre, maize leaf, goosegrass, banana false stem and untreated sisal fibres (USF) may be attributed to the small and different proportions of steriochemically open and relatively soluble active compounds such as tannins and glycosides relative to cellulose in maize leaf, goosegrass, banana false stem and inulin relative to cellulose in untreated sisal fibres [33, 34]. The presence of these compounds in the biomass is attributable to preparation procedures employed which did not involve removal of the water soluble impurities from the biomass. Aloe vera leaf biomass shows higher fluoride adsorption than sisal fibres, maize leaf, goosegrass and banana false stem biomass as shown in figure 4 . This can be attributed to the presence of mannose polymers $[30,31]$ whose stereochemistry is likely to expose more hydroxyl groups in it than cellulose polymers as seen in compound $b$ in figure 5 above. Our findings also reveal that, the difference in number of active sites present in the active compound as represented by the number of hydroxyl functional groups has little if any role to play in fluoride removal capacity of plant biomass as the number of hydroxyl groups per ring in the cellulose and inulin is 3 and 3.5 respectively.

\section{Conclusion and Recommendations}

The present study has established the fluoride removal capacity of sisal fibres. It also compares the fluoride removal capacities of different plant biomasses at the same experimental conditions. The fluoride removal capacities of maize leaf, goose grass, banana false stem, untreated sisal fibre and Aloe vera leaf and sisal pith biomass are 4.1, 4.6, $7.1,26.6,29.4$ and $47.3 \%$ respectively. This was obtainable at the optimized conditions of defluoridation by sisal fibres. Since the biomasses have the hydroxyl groups in relatively similar proportions, the variations in defluoridation efficiencies observed can be attributed to the stereochemistry and solubility which presents a major difference between their active compounds. It therefore suggests that, in addition to the type of active functional groups, the stereochemistry and solubility of the active compound play a significant role in fluoride removal capacity of plant biomass. It is thus recommended that, knowledge of the stereochemistry (the functional groups orientation to determine which stereochemistry supports more) and solubility of the active compounds present in different plant biomasses be taken on board when selecting plants biomass for defluoridation purposes.

\section{Acknowledgements}

This project was funded by Nelson Mandela African Institution of Science and Technology (NM-AIST) and the VRIL project.

\section{References}

[1] J. Fawell, K. Bailey, J. Chilton, E. Dahi, L. Fewtrell, and Y. Magara, "Fluorde in drinking water", IWA Publishing, London, 2006.

[2] R. C Meenakshi, R. C. Maheshwari, "Fluoride in drinking water and its removal", Journal of Hazardous Materials, Vol. 137, pp. 456-463, 2006.

[3] S. Modi, and R. Soni, "Merits and Demerits of different technologies of defluoridation for drinking water", IOSR Journal of Environmental Science, Toxicology and Food Technology, Vol. 3, pp. 24-27, 2013.

[4] A. Bhatnagar, E. Kumar, and M. Sillanpaa, "Fluoride removal from water by adsorption: A Review", Chemical Engineering Journal, Vol. 171, pp. 811-840, 2011.

[5] P. Loganathan, S. Vigneswaran, J. Kandasamy, and R. Naidu, "Defluoridation of drinking water using adsorption processes", Journal of Hazardous Materials, Vol. 248-249, pp. 1-19, 2013.

[6] P. Renuka, and K. Pushpanjali, "Review on defluoridation techniques of water", The International Journal of Engineering and Science, Vol. 2, pp. 86-94, 2013.

[7] S.M.I. Sajidu, W.R.L. Masamba, B. Thole, J.F. Mwatseteza, "Groundwater fluoride levels in villages of Southern Malawi and removal studies using bauxite", International Journal of Physical Sciences, Vol. 3, pp. 001-011, 2008. 
[8] M. Malakootian, M. Moosazadeh, N. Yousefi, and A. Fatehizadeh, "Fluoride removal from aqueous solution by pumice: case study on Kuhbonan water", African Journal of Environmental Science and Technology, Vol. 5, pp. 299-306, 2011.

[9] N.P. Kumar, N.S. Kumar, and A. Krishnaiah, "Defluoridation of water using Tamarind (Tamarindus indica) fruit cover: Kinetics and equilibrium studies", J. Chil. Chem. Soc, Vol. 57, pp. 1224-1131, 2012.

[10] P.K. Pandey, M. Pandey, R. Sharma, "Defluoridation of water by biomass;Tinospora cordifolia", Journal of Environmental Protection, Vol. 3, pp. 610-616, 2012.

[11] P.S.P. Harikumar, C. Jaseela, and T. Megha, "Defluoridation of water using biosorbents", Natural Science, Vol. 4, 245-251, 2012 .

[12] A.K. Yadav, R. Abbassi, A. Gupta, and M. Dadashzadeh, "Removal of fluoride from aqueous solution and ground water by wheat straw, sawdust and activated bagasse carbon of sugarcane”, Ecological Engineering, Vol. 52, pp. 211-218, 2013.

[13] A. Balouch, M. Kolachi, F.N. Talpur, H. Khan, and M.I. Bhanger, "Sorption kinetics isotherm and thermodynamic modelling of defluoridation of groundwater using natural adsorbents", American Journal of Analytical Chemistry, Vol. 4, pp. 221-228, 2013.

[14] H.T. Mwakabona, M. Said, R.L. Machunda, and K.N. Njau, "Plant Biomasses for Defluoridation Appropriateness: Unlocking Their Potentials", Research Journal in Engineering and Applied Sciences, Vol. 3, pp. 167-174, 2014.

[15] C.M.V. Vardhan,and J. Karthkeyan, "Removal of fluoride from water using low-cost materials", International Water Technology Journal, Vol. 1 pp. 120-131, 2011.

[16] N. Lakshmaiah, P.K. Paranjape, and P.M. Mohan, "Biodefluoridation of fluoride containing water by a fungal biosorbent", Proceeding of the second international workshop on fluorosis prevention and defluoridation of water, [November 19-22, 1997, Addis Ababa, Ethiopia, pp. 123-126. 1997].

[17] X. Zhao, L. Zhang, and D. Liu, "Biomass recalcitrance, Part I: the chemical compositions and physical structures affecting the enzymatic hydrolysis of lignocellulose", Biofuels, Bioproduct \& Biorefining, DOI: 10.1002/bbb, 2012.

[18] H. S. Parmar, J. B. Patel, P. Sudhakar, and V.J. Koshy, "Removal of Fluoride from Water with Powdered Corn Cobs", Journal of Environmental Science and Engineering, Vol. 48, pp. 135-138, 2006.

[19] N. Gupta, V. Gupta, A.P. Singh, and R.P. Singh, "Defluoridation of Groundwater using Low Cost Adsorbent like Bagasse Dust, Aluminium Treated Bagasse Flyash, Bone Powder and Shell Powder", Bonfring International Journal of Industrial Engineering and Management Science, Vol. 4, pp. 72-75, 2014.

[20] S. Gaspard, S. Altenor, E.A. Dawsonc, P.A. Barnes, and A. Ouensanga, "Activated carbon from vetiver roots: Gas and liquid adsorption studies", Journoul of Hazardous Materials,
Vol.144, pp.73-81, 2007.

[21] M. Snigdha, S.S. Kumar, M. Sharmistha, and C. Deepa, "An Overview on Vetiveria Zizanioides", Research Journal of Pharmaceutical, Biological and Chemical Sciences, vol.4, pp.777-784, 2013.

[22] K. G. M. Bouafou, B. A. Konan, V. Zannou-Tchoko, S. Kati-Coulibally, "Potential Food Waste and By-products of Coffee in Animal Feed", Electronic Journal of Biology, vol.7, pp.74-80, 2011

[23] G. S. Ashworth, and P. Azevedo, "Agricultural wastes", Nova Science Publishers, Inc. New York. pp 160, 2009.

[24] M.K. Malde, R. Greiner-Simonsen, K. Julshamn,.and K. Bjorvatn, "Tealeaves may release or absorb fluoride depending on the fluoride content of water", Science of the Total Environment, vol.366, pp.915-917, 2006.

[25] S. Sharma, V.K. Varshney, "Chemical Analysis of Agave Sisalana Juice for Its Possible Utilization", Acta Chim. Pharm. Indica, vol.2, pp.60-66, 2012.

[26] C. S. Sundaram, , S. Meenakshi "Fluoride sorption using organic-inorganic hybrid type ion exchangers", Journal of Colloid and Interface Science, vol.333, pp.58-62, 2009.

[27] I.O. Oladele, J.A. Omotoyinbo, and J.O.T. Adewara, "Investigating the Effect of Chemical Treatment on the Constituents and Tensile Properties of Sisal Fibre", Journal of Minerals \& Materials Characterization \& Engineering, vol.9, pp.569-582, 2010.

[28] N.K. Mondal, R. Bhaaumik, T. Baur, B.A. Das, P. Roy, and J.K. Datta, "Studies on defluoridation of water by tea ash: an unconventional biosorbent", Chem. Sci. Trans., vol.1, pp.239-256, 2012.

[29] K. Li, S. Fu, H. Zhan, Y. Zhan, and L.A. Lucia, "Analysis of the chemical composition and morphological structure of banana pseudo-stem", BioResources, vol5, pp. 576-585, 2010.

[30] T. Choche, S. Shende, and P. Kadu, "Extraction and Identification of Bioactive Components from Aloe barbadensis Miller", Research and Reviews, Journal of Pharmacognsoy and Phytochemistry, vol.2, pp.14-24, 2014.

[31] V.K. Chandegara, and A.K. Varshney, "Aloe vera L. Processing and Products: A review", Int. J. Med. Arom. Plants, vol. 3, pp. 492-506, 2013.

[32] S. L. Fávaro, T. A. Ganzerli, A. G. V. de Carvalho Neto, O. R. R. F. da Silva, and E. Radovanovic, "Chemical, morphological and mechanical analysis of sisal fiber-reinforced recycled high-density polyethylene composites", eXPRESS Polymer Letters, vol. 4, pp. 465-473, 2010.

[33] P.C. Onyenekwe, O.E. Okereke, and S. O. Owolewa, "Phytochemical Screening and Effect of Musa paradisiaca Stem Extrude on Rat Haematological Parameters", Current Research Journal of Biological Sciences, vol.5, pp. 26-29, 2013.

[34] M. Iqbal, and C. Gnanaraj, "Eleusine indica L. possesses antioxidant activity and precludes carbon tetrachloride (CCl4)-mediated oxidative hepatic damage in rats", Environ Health Prev Med., vol.17, pp. 307-315, 2012. 